\title{
Material Characteristics of Hair Cuticles after Hair Oil Treatment
}

\author{
Chia-Ling Chang, Tsung-Han Ho, ${ }^{1}$ and Te-Hua Fang ${ }^{2 *}$ \\ Department of Beauty and Health Care, Min-Hwei Junior College of Health Care Management, \\ No. 1116, Sec. 2, Zhongshan E. Rd., Liuying Dist., Tainan City 73658, Taiwan, R.O.C. \\ ${ }^{1}$ Department of Chemical and Materials Engineering, National Kaohsiung University of Applied Sciences, \\ No. 415, Jiangong Rd., Sanmin Dist., Kaohsiung City 80778, Taiwan, R.O.C. \\ ${ }^{2}$ Department of Mechanical Engineering, National Kaohsiung University of Applied Sciences, \\ No. 415, Jiangong Rd., Sanmin Dist., Kaohsiung City 80778, Taiwan, R.O.C.
}

(Received April 28, 2017, 2016; accepted September 14, 2017)

Keywords: atomic force microscopy, human hair, essential oil, Fourier-transform infrared spectrometer

In this paper, the cuticle characteristics of hair after oil treatment are discussed and analyzed. Hair lubrication mechanics were measured through atomic force microscopy (AFM), friction force microscopy (FFM), and Fourier-transform infrared (FTIR) spectrometry. From experimental results, the destruction and surface roughness of human hair treated with hair oil were evaluated. A homemade hair oil formula was applied and the treatment time was varied to observe the effects of hair care formulations on hair cuticles and surfaces. The results indicated that the extent of differences in hair cuticles varied according to different hair oil heating times. The adhesion force of human hair was approximately $17.0-36.8 \mathrm{nN}$. The results revealed high peaks associated with the increased $\mathrm{CH}_{2}$ intensity. Regions of approximately $2352-2938 \mathrm{~cm}^{-1}(-\mathrm{C}-\mathrm{C}-$ $\mathrm{H}-)$ alkyl absorption peaks and approximately $3441 \mathrm{~cm}^{-1}(-\mathrm{N}-\mathrm{H}-)$ amino acid absorption peaks were observed. An increasing trend of alkyl absorption peaks was also indicated. The observed $1361 \mathrm{~cm}^{-1}$ (amide, $-\mathrm{CN}-$ ) aliphatic absorption peaks and $1626 \mathrm{~cm}^{-1}(>\mathrm{C}=\mathrm{O})$ amino acid cysteine absorption peaks were typical effects of external factors on polypeptide hair fibers. The use of FTIR enabled the observation of changes in hair protein composition and surface structure.

\section{Introduction}

The booming and growing hair care market has led to the continued research and development of raw materials used in hair care and hair care formulations in order to meet consumer expectations for hair care efficacy. In the market for hair care products, the annual growth in global sales was $4.4 \%$ from 2006 to 2010 as compared with the average annual growth of $3.3 \%$ from 2001 to 2005. Global sales in the hair care market are expected to be as high as 371 million US dollars. Hence, there are tremendous worldwide opportunities in the hair care market. ${ }^{(1)}$

Most individuals strive for healthy and beautiful hair. However, beautiful hair requires special care, as environmental and climatic impacts coupled with the pursuit of modern and popular aids such as hair dyes and chemical perms often lead to harmful consequences such as dry hair, broken hair, discolored hair, bifurcations in the hair strands, lackluster hair, and moisture loss. ${ }^{(2)}$ These factors inhibit the normal growth of hair follicles and cuticles, and cause serious damage to

"Corresponding author: e-mail: fang.tehua@msa.hinet.net http://dx.doi.org/10.18494/SAM.2017.1707 
the hair. Hence, to restore the elasticity and luster of hair, damaged hair must be systematically repaired. ${ }^{(3)}$

Figure 1 shows the anagen cycle of the hair cuticle structure. According to this cycle, hair growth occurs in three stages, namely, the anagen, recession, and dormancy growth stages. The increase in hair growth mostly occurs at the anagen stage. In this stage, the fastest hair growth is observed and results in a large number of hair follicles. In the recession stage, the degradation of hair stops hair growth, hair follicle cells gradually die, and atrophy occurs at the bottom of the hair root. In the dormancy growth or telogen stage, there is dermal papilla hair loss and the hair stops growing. ${ }^{(4)}$

Hair oil formulations mainly comprise oil-based formulations. Oil (essential oil) is an aromatic substance commonly found in various parts of a plant, such as the roots, trunk, bark, tree stems, leaves and flowers. The oil is extracted from plants with considerable effectiveness and purpose, and is usually used in related industries such as perfumes and cosmetics. ${ }^{(5)}$

Hair contains protein in the form of amino acid protein. The amino acid protein is classified biologically as an organic compound, mainly composed of amine $\left(-\mathrm{NH}_{2}\right)$ and carboxylic acid $(-\mathrm{COOH})$ functional groups. An amino acid is the most important and basic unit of protein. Protein is an important active molecule, and protein in vivo activities includes enzyme-catalyzed metabolism (also known as "enzyme"). The dehydration and condensation of different amino acids form a peptide (original protein fragment) and produce the precursor protein.

Recent enhancements in the national standard of living have resulted in consumers devoting increasing attention to their appearance and beauty. Hence, the demand for cosmetic products has increased. Moreover, for many consumers, having beautiful black hair is an important objective, and thus, the quality and health of the hair are as important as healthy skin. ${ }^{(6)}$ As a result of this, there is an increasing number of products available on the market, which claim to condition and nourish the hair.

In this paper, atomic force microscopy (AFM), friction force microscopy (FFM), and Fouriertransform infrared spectrometry (FTIR) methods were used to investigate the effects of hair oil applications heated at different time periods on the hair surface. The frictional behavior, adhesion, and structure of hair cuticles were examined. ${ }^{(7,8)}$ The methods can possibly be used for surface or tactile sensor applications of organic surface or soft materials.

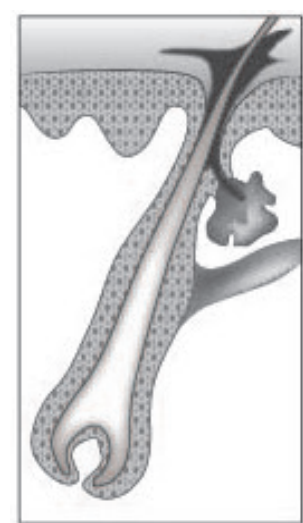

(a)

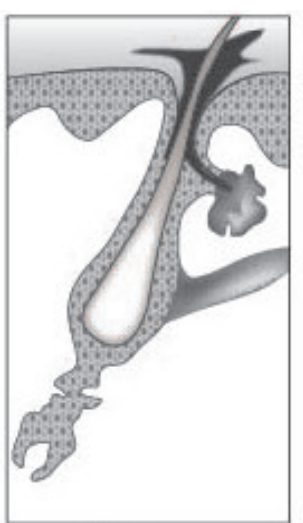

(b)

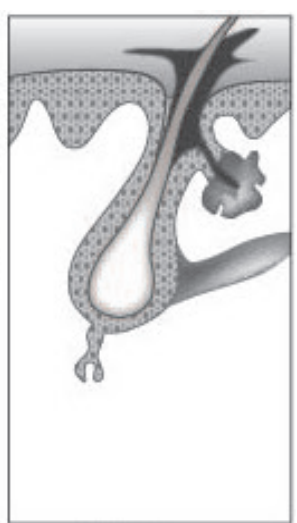

(c)

Fig. 1. Hair cycle: (a) anagen, (b) catagen, and (c) telogen. 


\section{Experimental Procedure}

\subsection{Sample preparation}

An approximately 50-cm-long hair sample was obtained near the scalp from an Asian woman. The hair was pretreated by shaking it in a solution of deionized water for $20 \mathrm{~min}$ and then treating it with nitrogen. Then, the clean hair was dried. This reduced the effects of external pollutants (such as air and dust) on the accuracy of the experimental results. The experimental procedure involved a base oil (jojoba oil). Five types of essential oils, namely, rose geranium, eucalyptol rosemary, clary sage, bergamot, and frankincense, were added to the base oil. The effect of the five oils on hair quality varied. The self-formulations were mixed and allowed to stand in an oven for heat treatment. The heating temperature was approximately $60^{\circ} \mathrm{C}$, and the different heating times were 10, 20, 30, 40, 50, and $60 \mathrm{~min}$. Furthermore, a group without any oil was observed. In addition, a group with no oil added to the base oil (that is, the base oil by itself) was heated for $10 \mathrm{~min}$. The changes observed in the experiment are detailed in Table 1.

\subsection{Measurements}

AFM (Bucker) and FFM were used to perform surface roughness and friction force measurements. AFM and friction force measurements were conducted with a Bruker system under ambient conditions using a $\mathrm{Si}_{3} \mathrm{~N}_{4}$ square-pyramidal tip in the contact mode. FTIR was performed with a Perkin Elmer spectrum 100 system. $^{(9)}$

\section{Results and Discussion}

\subsection{AFM}

Figure 2 presents the AFM images of the surface morphology of a hair sample at different heat treatment temperatures. The AFM images of the surface morphology of hair keratin are shown in Fig. 3(a) 0 (healthy original hair), (b) 10, (c) 20, (d) 30, (e) 60, and (f) $10 \mathrm{~min}$ (base oil). The results

Table 1

Content, time, and temperature of homemade essential oil for hair treatment.

\begin{tabular}{|c|c|c|}
\hline Sample & Formula & Time/temperature \\
\hline A & $\begin{array}{c}\text { Rose geranium 1D + Eucalptol rosemary 2D + Clary sage 1D } \\
+ \text { Bergamot 1D + Mastic 1D + Jojoba } 10 \mathrm{ml}\end{array}$ & $10 \mathrm{~min} / 60^{\circ} \mathrm{C}$ \\
\hline B & $\begin{array}{c}\text { Rose geranium 1D + Eucalptol rosemary 2D + Clary sage 1D } \\
+ \text { Bergamot 1D + Mastic 1D + Jojoba } 10 \mathrm{ml}\end{array}$ & $20 \mathrm{~min} / 60^{\circ} \mathrm{C}$ \\
\hline $\mathrm{C}$ & $\begin{array}{c}\text { Rose geranium 1D + Eucalptol rosemary 2D + Clary sage 1D } \\
+ \text { Bergamot 1D + Mastic 1D + Jojoba } 10 \mathrm{ml}\end{array}$ & $30 \mathrm{~min} / 60^{\circ} \mathrm{C}$ \\
\hline $\mathrm{D}$ & $\begin{array}{c}\text { Rose geranium 1D + Eucalptol rosemary 2D + Clary sage 1D } \\
+ \text { Bergamot 1D + Mastic 1D + Jojoba } 10 \mathrm{ml}\end{array}$ & $40 \mathrm{~min} / 60^{\circ} \mathrm{C}$ \\
\hline E & $\begin{array}{c}\text { Rose geranium 1D + Eucalptol rosemary 2D + Clary sage 1D } \\
+ \text { Bergamot 1D + Mastic 1D + Jojoba } 10 \mathrm{ml}\end{array}$ & $50 \mathrm{~min} / 60^{\circ} \mathrm{C}$ \\
\hline $\mathrm{F}$ & $\begin{array}{c}\text { Rose geranium 1D + Eucalptol rosemary 2D + Clary sage 1D } \\
+ \text { Bergamot 1D + Mastic 1D + Jojoba } 10 \mathrm{ml}\end{array}$ & $60 \min / 60{ }^{\circ} \mathrm{C}$ \\
\hline $\mathrm{G}$ & Jojoba $10 \mathrm{ml}$ & $10 \mathrm{~min} / 60{ }^{\circ} \mathrm{C}$ \\
\hline
\end{tabular}




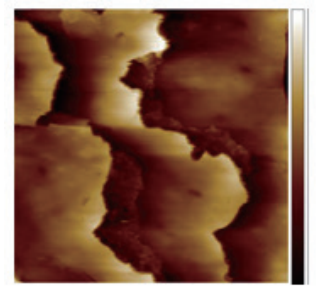

(a)

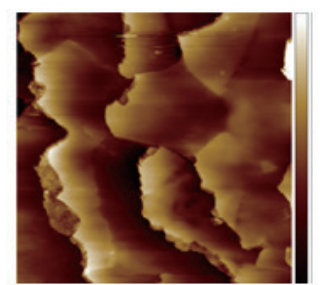

(d)

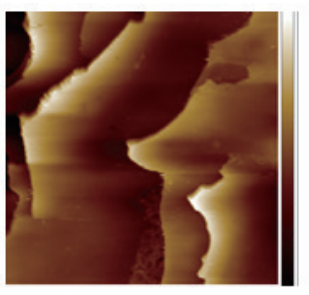

(b)

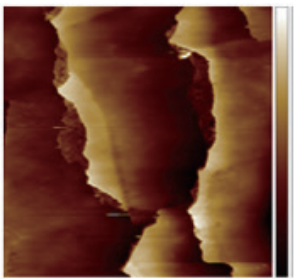

(e)

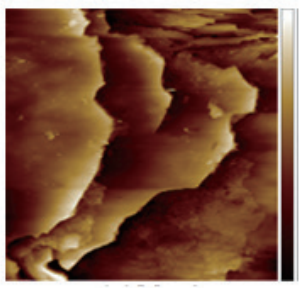

(c)

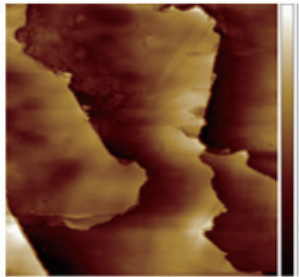

(f)

Fig. 2. (Color online) AFM images of human hair surface morphology after application of different hair oil formulae at different heat treatment times. (a) 0, (b) 10, (c) 20, (d) 30, (e) 60, and (f) $10 \mathrm{~min}$ (base oil).

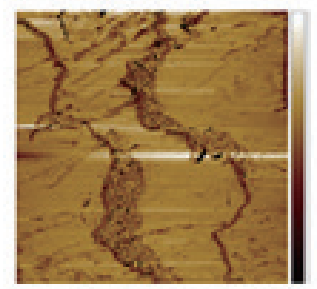

(a)

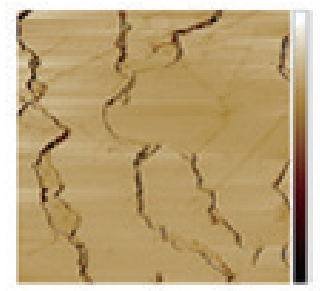

(d)

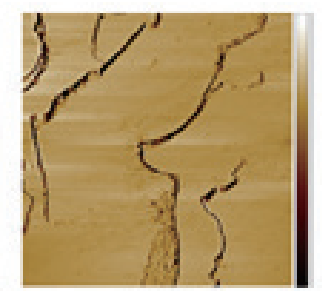

(b)

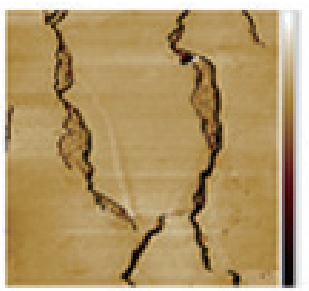

(e)

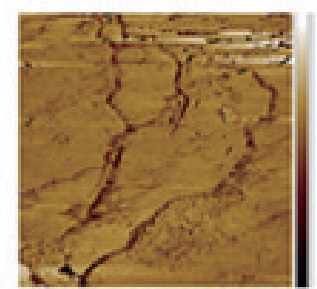

(c)

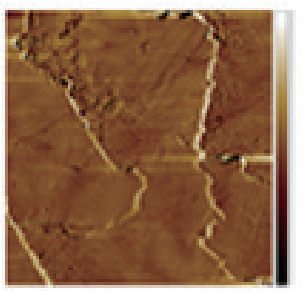

(f)

Fig. 3. (Color online) FFM images of human hair surface morphology after application of different hair oil formulae at different heat treatment times. (a) 0, (b) 10, (c) 20, (d) 30, (e) 60, and (f) $10 \mathrm{~min}$ (base oil).

showed that the observed morphology and roughness of the hair cuticle surface were affected by different hair oil formulae with different heating times. The samples with different heating times exhibited significantly different surface roughnesses.

The AFM images in Fig. 2 show that AFM images of human hair surface morphology after application of different hair oil formulae at different heat treatment times: (a) 0, (b) 10, (c) 20, (d) 30, (e) 60, and (f) $10 \mathrm{~min}$ (base oil). The 0 min healthy original hair exhibited a smoother surface structure because the healthy hair specimen sample was not subjected to external physical and chemical damage, and thus, the hair cuticle by itself is very healthy. In Figs. 2(a)-2(f), the cuticles of the samples displayed cuticle surface root-mean-square roughness $(R q)$ values of 5.8, 10.0, $13.4,9.3,14.1$, and $6.30 \mathrm{~nm}$, respectively. Healthy hair by itself had a low surface roughness. The 
highest surface roughness was observed for the 60 min essential hair oil; that is, the increased hair heating time could lead to the volatilization or deterioration of the active ingredient formulation and reduction in conditioning effect. The essential oils and the base oil by itself belonged to the category of vegetable oil conditioners. Hence, when the heating time was very long, oxides were formed and the oil degenerated. This in turn may lead to poor hair care effects and other phenomena.

\subsection{FFM}

Figure 3 shows FFM images obtained at different essential oil heating times: (a) 0 min (untreated healthy hair), (b) 10, (c) 20, (d) 30, (e) 60, and (f) $10 \mathrm{~min}$ (base oil).

The healthy hair from the sample to which no oils were heated and applied displayed a good surface structure. However, when oils were applied, the oils had to be heated so that the oil could permeate in the hair and result in changes in the structure of keratin. Thus, the hair oil was heated for different heating times of 10,20,30,60, and $10 \mathrm{~min}$ (only the base or jojoba oil). The results indicate that the highest hair friction force was observed in the sample heated for $30 \mathrm{~min}$. In this study, the hair oil heated for 60 min exhibited better surface friction structures. The formulation with the base oil by itself that was heated for 10 min was less effective than the hair formulations that were heated for $60 \mathrm{~min}$.

Figures 4(a) and 4(b) show the surface roughnesses and friction forces of the samples for different heat treatment times of the hair oil formulations. For the different heating times of 10, 20, 30,60 , and $10 \mathrm{~min}$ (only the base or jojoba oil), the root-mean-square surface roughness $(R q)$ values of the cuticles were 10.0, 13.4, 9.3, 14.1, and $6.3 \mathrm{~nm}$, respectively. The highest surface roughness was observed for the $10 \mathrm{~min}$ (no-oil-added) sample. These results are consistent with the AFM images of the lower effective surface. The friction forces of the hair cuticles after the different heating times of 10, 20, 30, 60, and $10 \mathrm{~min}$ (only the base or jojoba oil) were $0.083,0.082,0.089,0.079$, and $0.080 \mathrm{~V}$, respectively.

The samples treated for 60 and $10 \mathrm{~min}$ (only the base oil) had small surface roughnesses. The proximity effects for the samples treated for 20 and $10 \mathrm{~min}$ were not significant. The sample treated for $30 \mathrm{~min}$ had a large surface roughness.

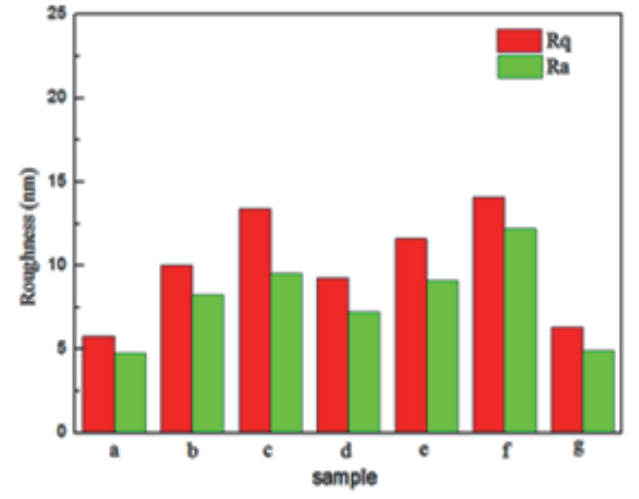

(a)

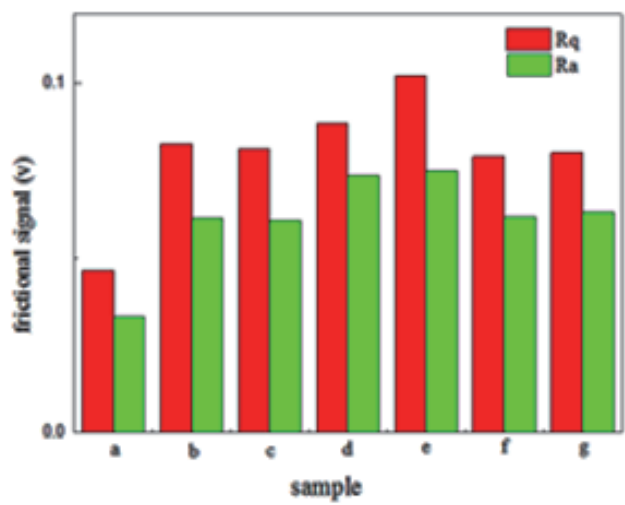

(b)

Fig. 4. (Color online) (a) Surface roughnesses and (b) friction forces of samples obtained at different hair oil recipe treatment times of 0 (original hair), 10, 20, 30, 40, 60, and $10 \mathrm{~min}$ (jojoba oil) at different locations. 


\subsection{Force-displacement curve}

Figure 5 shows a force-displacement plot for the hair samples with hair oils at different heating times. The adhesion force could be obtained from the snap back horizontal distance of the cantilever probe. The adhesion forces for the hair oils at different heating times of $0,10,20,30$, 60 , and $10 \mathrm{~min}$ (base oil) were 17.0, 31.9, 32.8, 36.8, 25.6, and $33.5 \mathrm{nN}$, respectively. The maximum adhesion force of the hair surface in this study occurred in the case of the hair oil heated for 30 $\min$.

Figure 6 presents the force-displacement curves of the samples at different heating times of 0 (untreated healthy hair), 10, 20, and $30 \mathrm{~min}$. The contact point between the tip and the sample was reached when the probe tip approached the hair surface. The adhesion occurred because the AFM probe tip was attracted by the gravitational pull between the hair surface and the probe;
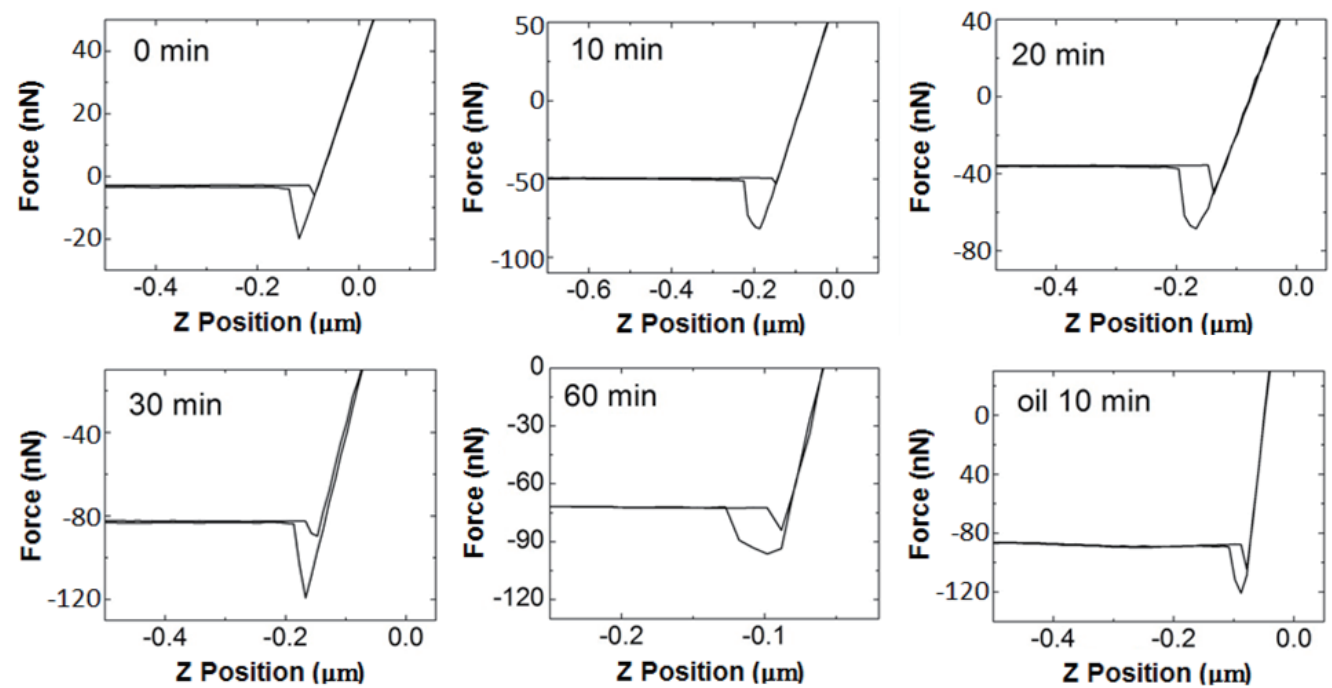

Fig. 5. Force-displacement plot for hair samples with hair oils at different heating times.

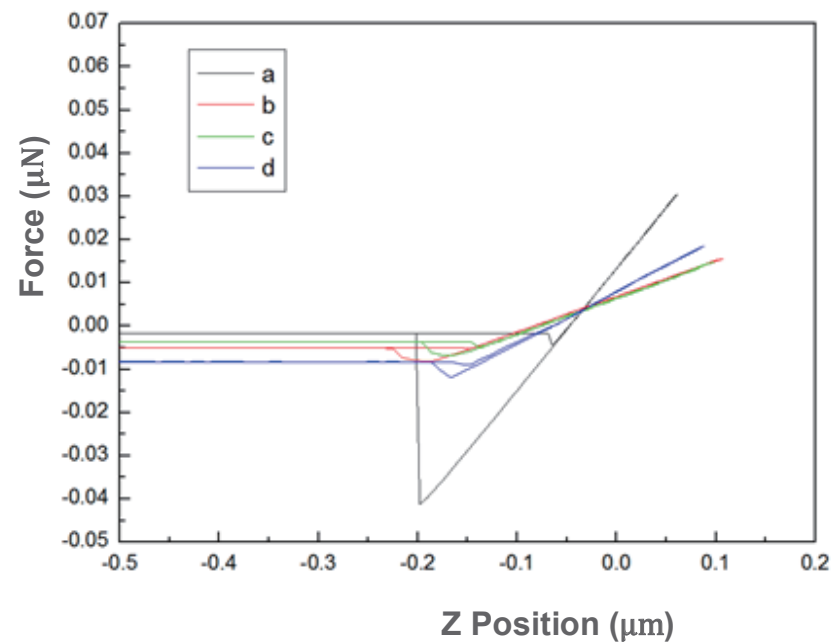

Fig. 6. (Color online) Force-displacement curves of samples at different heating times of (a) 0 (original hair), (b) 10, (c) 20, and (d) $30 \mathrm{~min}$. 


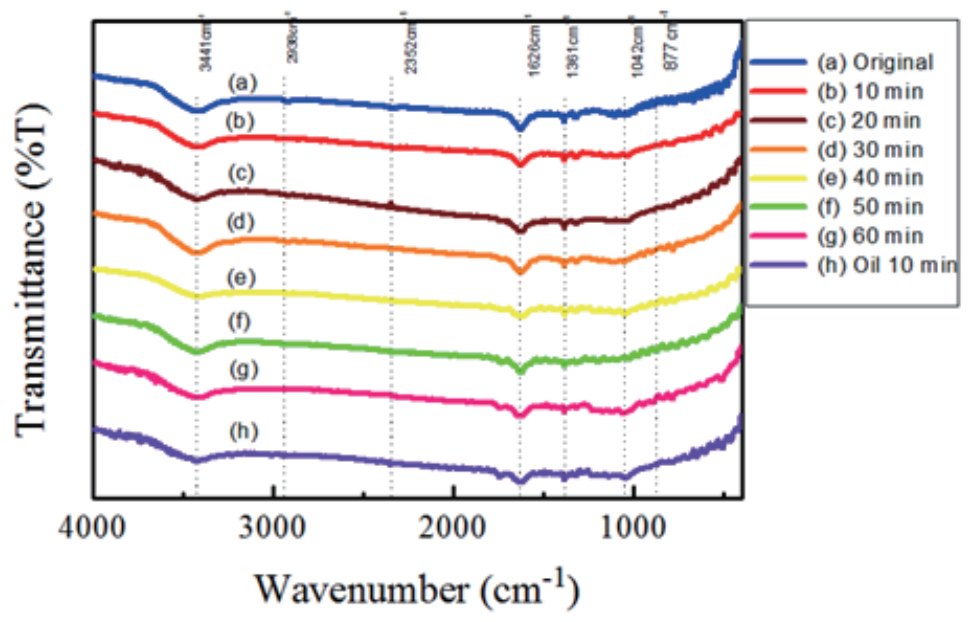

Fig. 7. (Color online) FTIR spectra of hairs subjected to different homemade hair oil recipes.

hence, the probe bent to the side of the hair sample. The adhesive forces of the hair for different hair oil heating times of $0,10,20$, and 30 min were $-0.0017,-0.00319,-0.00328$, and -0.00368 $\mathrm{nN}$, respectively. A strong viscous force was measured for the untreated healthy hair (heated for 0 $\min )$.

\section{$3.4 \quad$ FTIR}

The scanning spectral range was $1000-4000 \mathrm{~cm}^{-1}$ and the scanning resolution was $1 \mathrm{~cm}^{-1}$. The scans were performed sixteen times to monitor the functional group Atlas (scanning spectral range, $1000-4000 \mathrm{~cm}^{-1}$; scanning resolution, $1 \mathrm{~cm}^{-1}$ ).

The human hair was analyzed by FTIR spectroscopy. Figure 7 presents the FTIR spectra reflecting the hair repair effects of the hair formulations at different heating times. The results reveal high peaks associated with the increased $\mathrm{CH}_{2}$ intensity in approximately $2352-2938 \mathrm{~cm}^{-1}$ regions of $(-\mathrm{C}-\mathrm{C}-\mathrm{H}-)$ alkyl absorption peaks and $3441 \mathrm{~cm}^{-1}$ regions of $(-\mathrm{N}-\mathrm{H}-)$ amino acid absorption peaks. An increasing trend of alkyl absorption peaks was observed, and $1361 \mathrm{~cm}^{-1}$ (amide, $-\mathrm{C}-\mathrm{N}-$ ) aliphatic amine absorption peaks and typical $1626 \mathrm{~cm}^{-1}$ regions of $(>\mathrm{C}=\mathrm{O})$ amino acid cysteine absorption peaks were also observed. This is because the polypeptides in hair fibers are affected by external factors, and this leads to the bonding of amino acid molecules. The use of hair oil gradually enhances the absorption. An increasing adsorption trend was observed when the hair oil was heated for $30 \mathrm{~min}$. The absorption width was constant when the hair oil was heated for $40 \mathrm{~min}$, and the absorption peak weakened when the hair oil was heated for $50 \mathrm{~min}$. After this, the absorption peak started to gradually increase. The width increased and a more gentle absorption peak was observed with respect to the oil-free base oil group after 10 min of heating.

\section{Conclusions}

In this work, the friction and surface properties of hair cuticle surfaces subjected to hair care with different hair oil heating times were measured. The methods can possibly be used for 
surface and soft material sensing application. From this study, several important conclusions were obtained as follows:

(1) A scanning probe microscopy measurement of hair treated with widely used hair care oils indicated effective surface morphology and structural properties.

(2) The force-displacement curves suggested that the adhesion force varied on the sample surfaces. The adhesion force of human hair was approximately $17.0-36.8 \mathrm{nN}$.

(3) The root-mean-square surface roughness $(R q)$ values for hair cuticle surfaces with different hair oil heating times of (a) 0 (healthy original hair), (b) 10, (c) 20, (d) 30, (e) 60, and (f) $10 \mathrm{~min}$ (base oil) were $5.8,10.0,13.4,9.3,14.1$, and $6.30 \mathrm{~nm}$, respectively.

(4) The root-mean-square surface roughness $(R q)$ values of hair after oil heating times of $0,10,20$, and 30 min ranged from 5.8 to $9.3 \mathrm{~nm}$.

(5) High peaks were associated with the increased $\mathrm{CH}_{2}$ intensity in approximately 2352-2938 $\mathrm{cm}^{-1}$ regions of $(-\mathrm{C}-\mathrm{C}-\mathrm{H}-)$ alkyl absorption and $3441 \mathrm{~cm}^{-1}$ regions of $(-\mathrm{N}-\mathrm{H}-)$ amino acid absorption. Increasing trends of alkyl, $1361 \mathrm{~cm}^{-1}$ (amide, $-\mathrm{CN}-$ ) aliphatic amine, and 1626 $\mathrm{cm}^{-1}(>\mathrm{C}=\mathrm{O})$ absorption peaks typical of the amino acid cysteine were also observed.

\section{Acknowledgments}

This work was partially supported by the Ministry of Science and Technology of Taiwan under MOST 103-2221-E151-001 MY3.

\section{References}

1 J. E. Lai-Cheong and J. A. McGrath: Medicine 41 (2013) 317.

2 C. L. Chang, T. H. Ho, and T. H. Fang: Math. Problems Eng. 2015 (2015) 985393. doi: http://dx.doi.org/10.1155/2015/985393

3 K. Schaefer: http://www.cosmeticsandtoiletries.com/formulating/ingredient/moisturizer/7653302.html (Polymers for Personal Care Products and Cosmetics).

4 T. H. Fang, S. H. Kang, Z. H. Hong, and C. D. Wu: Micron 43 (2012) 407.

5 I. P. Seshadri and B. Bhushan: Acta Mater. 56 (2008) 774.

6 J. R. Smith, J. Tsibouklis, T. G. Nevell, and S. Breakspear: Appl. Surf. Sci. 285 (2013) 638.

7 C. L. Chang, T. H. Ho, and T. H. Fang: J. Chin. Soc. Mech. Eng. 36 (2015) 563.

8 P. Dumas, N. Jamin, J. Teilland, L. Miller, and B. Beccard: Faraday Discuss. 126 (2004) 289.

9 R. R. Wickett and J. Jachowicz: Handbook of Cosmetic Science and Technology, 3rd ed. (Elsevier Advanced Technology, Amsterdam, 1993) p. 705.

\section{About the Authors}

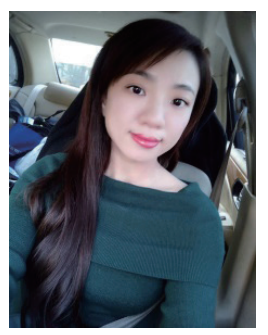

Chia-Ling Chang received her B.S. and M.S. degrees from Chia Nan University of Pharmacy \& Science, Taiwan, in 2003 and 2007, respectively and her Ph.D. degree from National Kaohsiung University of Applied Sciences, Taiwan, R.O.C., in 2016. Since 2016, she has been an assistant professor at the Department of Beauty and Health Care, Min-Hwei Junior College of Health Care Management, Taiwan, R.O.C. Her guidance for students to participate in beauty-related competitions won numerous awards (2006-2017). Her research interests are in beauty, hair, aromatherapy, and cosmetic. 


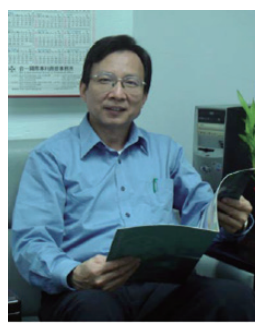

Tsung-Han Ho received his B.S. and M.S. degrees from National Taiwan University of Science and Technology, Taiwan, R.O.C., in 1982 and 1986, respectively, and his Ph.D. degree from National Cheng Kung University, Taiwan, R.O.C., in 1994. Since 2000, he has been a professor at National Kaohsiung University of Applied Sciences, Taiwan, R.O.C. His research interests are in chemical engineering and polymeric materials for electronic applications.

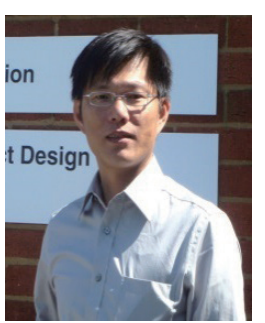

Te-Hua Fang received his B.S. degree from National Taiwan University of Science and Technology, Taiwan, in 1993 and his M.S. and Ph.D. degrees from National Cheng Kung University, Taiwan, in 1995 and 2000, respectively. He has published over 300 international journal publications in nanotechnology, computational materials science, and mechanical engineering, as well as numerous publications on technology, energy, and nanoscience issues. He has received memberships and honors from the First Class Research Award, National Science Council (NSC), Taiwan (2005-2007), Mr. Wu Da-Yo Memorial Award, NSC (2007-2009), and Outstanding Research Award, NSC (2011). He is a Fellow of the Institution of Engineering and Technology (IET, UK) and Taiwan Institute of Knowledge Innovation. His research interests are in nanotechnology, molecular dynamics, and surface science. 